\title{
Determination of antibiotic sensitivities by the Sensititre system
}

\author{
IAN PHILLIPS, CHRISTINE WARREN, AND PAMELA M. WATERWORTH \\ From the Department of Microbiology, St. Thomas's Hospital Medical School, London SE1 7EH, and the \\ Department of Clinical Microbiology, University College Hospital, London WC1E 6AU, UK
}

SUMMARY The Sensititre system provides antibiotics dried in microtitre trays in appropriate concentrations for the determination of minimum inhibitory concentrations (MIC) when organisms are added in liquid culture medium and incubated overnight. Results with a variety of mediafor Gram-negative bacilli tested with ampicillin, carbenicillin, cephaloridine, and gentamicin, staphylococci with penicillin, cloxacillin, fusidic acid, and gentamicin, and streptococci with penicillin, ampicillin, cephaloridine, and erythromycin-were usually very similar to those of agar dilution tests. Discrepant results were found in a few situations, and in some cases, especially those involving borderline resistance to fusidic acid and gentamicin among staphylococci and Gramnegative bacilli, we have been unable to suggest modifications to produce the right results. Despite these problems, fortunately few and identifiable, we recommend the system especially for use in laboratories that determine the MICs infrequently.

Most microbiologists in Britain consider that disc tests are adequate for routine antibiotic sensitivity testing and that the determination of minimum inhibitory concentrations (MIC) is rarely required. However, most would also like to determine MICs sometimes, for example, on organisms isolated from the blood of patients with endocarditis or from infections that fail to respond to treatment, and also on organisms that give equivocal results with a disc test. Unfortunately, the fact that MICs are required infrequently often results in their not being done at all because the essential skill, experience, or time are not available.

In this context, a commercial source of microtitre trays with wells containing appropriate amounts of dehydrated antibiotics, stable at room temperature and requiring only the addition of inoculated broth followed by incubation-the Sensititre system (Seward Laboratories) - was of considerable interest. We decided to assess it with the needs of the diagnostic laboratory in mind.

\section{Material and methods}

Each Sensititre tray contained 10 doubled dilutions of four antibiotics in duplicate, with two drug-free control wells, so that in clinical practice a control

Received for publication 7 December 1977 bacterium could be included in the investigation of each strain. There were three trays. The first, for Gram-negative bacilli, contained ampicillin, cephaloridine, and gentamicin in a range of concentrations from 16 to $0.03 \mathrm{mg} / \mathrm{l}$ and carbenicillin from 256 to $0.5 \mathrm{mg} / \mathrm{l}$. The second tray, for staphylococci, contained penicillin, cloxacillin, sodium fusidate, and gentamicin in concentrations from 8 to $0.015 \mathrm{mg} / \mathrm{l}$. At the end of the major part of the study it became clear that the range of concentrations was not always optimal. New ranges were then prepared and given limited assessment. For Gram-negative bacilli, concentrations of gentamicin ranged from 16 to $0.01 \mathrm{mg} / \mathrm{l}$, ampicillin and cephaloridine from 64 to $0.06 \mathrm{mg} / \mathrm{l}$, and carbenicillin from 512 to $0.5 \mathrm{mg} / \mathrm{l}$. For staphylococci, concentrations of penicillin ranged from 4 to $0.003 \mathrm{mg} / \mathrm{l}$, and cloxacillin, fusidate, and gentamicin from 8 to $0.007 \mathrm{mg} / \mathrm{l}$. For streptococci, the new concentrations for all four antibiotics ranged from 4 to $0.003 \mathrm{mg} / \mathrm{l}$. One further modification, given limited assessment, was the addition by the manufacturers of $3.5 \%$ sodium chloride to wells containing cloxacillin in an attempt to detect resistance.

Clinically important bacteria were chosen from routine clinical isolates in St. Thomas' and University College Hospitals to represent a range of antibiotic sensitivity. There were $45 \mathrm{Gram}$-negative bacilli (including nine strains of Escherichia coli, 10 
klebsiella, three providencia, nine proteus, one enterobacter, three citrobacter, and 10 Pseudomonas aeruginosa) and $80 \mathrm{Gram}$-positive cocci (including 44 Staphylococcus aureus, one Staphylococcus albus, and 35 streptococci).

Inocula were prepared by overnight incubation of broth cultures which were then diluted to give approximately $10^{6}$ colony-forming units (cfu)/ml. The volume of broth added to each well was $50 \mu \mathrm{l}$. The inoculum was that advocated by the manufacturers, but as the method recommended by them actually produced a heavier inoculum a few tests were done to assess the effect of increasing it to about $10^{8} \mathrm{cfu} / \mathrm{ml}$.

Each department tested two different broths-at St. Thomas' Hospital DST (Oxoid specially prepared) and Mueller Hinton (Oxoid CM405), and at University College Hospital Wellcotest (Wellcome) and Isosensitest (Oxoid CM473). A few experiments were also carried out with Tryptone soya broth (Oxoid CM129) and Oxoid No. 2 broth (Oxoid CM67). Serum $10 \%$ was added to all media for the testing of streptococci.

MICs were also determined for all the strains by a plate dilution method, using the agar version of each of the four main media, with a similar inoculum applied with a multiple inoculator. Instead of serum, $5 \%$ saponin-lysed horse blood was added for streptococci. Where there were considerable discrepancies between Sensititre and plate MIC results, tube MICs were determined.

Several strains were tested repeatedly to assess the reproducibility of the method; in some of these tests we used Sensititre plates that had been kept at room temperature or, in a few cases, at $-20^{\circ}$ for three to four months.

Results were read in a specially designed viewer, and the endpoint was taken as the lowest concentration showing very little or no growth, as assessed by the absence or virtual absence of a button of cells at the bottom of each well.

In the assessment of results, MICs determined by the various methods were compared by the construction of regression lines and the determination of correlation coefficients by the method of least squares analysis.

\section{Results}

The type of growth varied with the organisms and was sometimes changed by the presence of an antibiotic. It frequently settled as a button, but sometimes the broth remained uniformly turbid or contained flocculent growth. In most cases, growth was easily detected and the endpoint was clear, but many streptococci grew poorly in all media despite the addition of serum.

MICs determined by the Sensititre system correlated well, with few exceptions, with those from solid media (Table 1). The general regression line equation, $y=0.88 x+1 \cdot 37$, obtained when results for all organisms were compared indicates that results for the Sensititre system were marginally higher than those determined conventionally. Results for the three groups show that this was true for Gram-negative bacilli and staphylococci but not for streptococci, for which results were almost identical by the two systems.

Table 2 compares the overall results of the two systems on the basis of the number of dilutions by which results differed. We were able to compare 1898 pairs of results: 885 were identical though it should be noted that this includes 399 in which both results were either above or below the range of concentrations tested. A further 627 differed from each other by only one concentration above or below, and 252 by two dilutions. In only 128 cases $(6.8 \%)$ did results differ by three or more concentrations.

These most discrepant results were found only among a few organisms and antibiotics. In most cases organisms appeared considerably more resistant by the Sensititre system. The most striking example is seen in row 11 of Table 2, which shows the numbers of organisms that grew in the top con-

Table 1 Correlation of MIC results determined by agar dilution and by Sensititre

\begin{tabular}{|c|c|c|c|c|c|c|}
\hline \multirow[t]{2}{*}{ Groups compared } & \multicolumn{2}{|c|}{ Mean $M I C^{*}(S D)$} & \multirow[t]{2}{*}{$a \dagger$} & \multirow[t]{2}{*}{$b \dagger$} & \multirow{2}{*}{$\begin{array}{l}\text { Correlation } \\
\text { coefficient }\end{array}$} & \multirow{2}{*}{$\begin{array}{l}\text { Standard } \\
\text { error }\end{array}$} \\
\hline & Agar & Sensititre & & & & \\
\hline All organisms & $\begin{array}{l}10 \cdot 26 \\
(2 \cdot 86)\end{array}$ & $\begin{array}{l}10 \cdot 25 \\
(2 \cdot 86)\end{array}$ & 0.88 & $1 \cdot 37$ & 0.87 & $1 \cdot 36$ \\
\hline Gram-negative bacilli & $\begin{array}{l}12 \cdot 7 \\
(2 \cdot 41)\end{array}$ & $\begin{array}{l}12.66 \\
(2.4)\end{array}$ & $0 \cdot 83$ & $2 \cdot 22$ & 0.81 & $1 \cdot 40$ \\
\hline Staphylococci & $\begin{array}{c}9 \cdot 32 \\
(1.98)\end{array}$ & $\begin{array}{c}9.32 \\
(1.94)\end{array}$ & 0.74 & $2 \cdot 59$ & 0.66 & $1 \cdot 46$ \\
\hline Streptococci & $\begin{array}{c}8 \cdot 38 \\
(2 \cdot 55)\end{array}$ & $\begin{array}{c}8 \cdot 51 \\
(2 \cdot 59)\end{array}$ & 0.90 & 1.03 & 0.94 & 0.86 \\
\hline
\end{tabular}

Expressed as $\log _{2}+11$.

In equation $y=a x+b$. 
Table 2 Comparison of results of MIC determinations by standard solid medium and Sensititre methods

\begin{tabular}{|c|c|c|c|c|c|c|c|c|c|c|c|c|c|c|}
\hline \multirow{3}{*}{\multicolumn{2}{|c|}{$\begin{array}{l}\text { No. of } \\
\text { Sensititre results }\end{array}$}} & \multicolumn{13}{|c|}{ Solid medium method: number of results } \\
\hline & & \multirow{2}{*}{$\begin{array}{l}\text { At or below } \\
\text { lowest } \\
\text { concentration }\end{array}$} & \multicolumn{10}{|c|}{ At concentrations } & \multirow{2}{*}{$\begin{array}{l}\text { Above } \\
\text { highest } \\
\text { concentration }\end{array}$} & \multirow[t]{2}{*}{ Total } \\
\hline & & & $1^{*}$ & 2 & 3 & 4 & 5 & 6 & 7 & 8 & 9 & 10 & & \\
\hline \multicolumn{2}{|l|}{$\begin{array}{l}\text { At or below lowest } \\
\text { concentration }\end{array}$} & $179 *$ & 0 & 53 & 16 & 1 & 0 & 0 & 0 & 0 & 0 & 0 & 0 & \\
\hline \multirow[t]{9}{*}{ At concentration } & 2 & 46 & 1 & 65 & 42 & 18 & 0 & 0 & 1 & 0 & 0 & 0 & $\begin{array}{l}0 \\
0\end{array}$ & $\begin{array}{l}249 \\
173\end{array}$ \\
\hline & 3 & 7 & 2 & 25 & 29 & 27 & 3 & 3 & 0 & 0 & 0 & 0 & 0 & 96 \\
\hline & 4 & 0 & 1 & 8 & 36 & 76 & 38 & 9 & 1 & 0 & 0 & 0 & 0 & 169 \\
\hline & 5 & 1 & 0 & 2 & 14 & 49 & 91 & 29 & 25 & 1 & 1 & 0 & C & 213 \\
\hline & 6 & 1 & 0 & 0 & 1 & 13 & 44 & 44 & 56 & 14 & 2 & 1 & 0 & 176 \\
\hline & 7 & 0 & 0 & 0 & 1 & 16 & 27 & 47 & 56 & 43 & 6 & 0 & 0 & 196 \\
\hline & 8 & 0 & 0 & 0 & 0 & 9 & 13 & 14 & 35 & 78 & 17 & 2 & 5 & 173 \\
\hline & 9 & 0 & 0 & 0 & 1 & 1 & 6 & 3 & 4 & 19 & 15 & 9 & 2 & 60 \\
\hline & 10 & 0 & 0 & 0 & 0 & 0 & 2 & 5 & 0 & 9 & 15 & 32 & 18 & 81 \\
\hline \multirow{3}{*}{\multicolumn{2}{|c|}{$\begin{array}{l}\text { Above highest } \\
\text { concentration } \\
\text { Total }\end{array}$}} & & & & & & & & & & & & & \\
\hline & & 0 & 0 & 0 & 2 & 0 & 2 & 14 & 13 & 16 & 21 & 23 & 220 & 311 \\
\hline & & 234 & 4 & 153 & 142 & 210 & 226 & 168 & 191 & 180 & 77 & 67 & 245 & 1898 \\
\hline
\end{tabular}

Figures in bold type are numbers of tests in which results were identical by the two systems.

*All lowest concentrations were labelled 1 and highest 10 .

centration of antibiotic in the Sensititre system but were much more sensitive by the agar-dilution method. Of the 47 results that differed by more than two dilutions in this row, 46 came from determinations of the sensitivity of staphylococci to penicillin, as is shown in Table 3. A second example is seen among organisms with MICs ranging from concentrations 3 to 7 in Table 2 by the agar method, but more than two concentrations higher by Sensititre. Of 58 discrepant results, 52 were again w th staphylococci, and the antibiotic in the case of the more extreme discrepancies was again penicillin in concentrations of 0.06 to $1 \mathrm{mg} / 1$ (concentrations 3 to 7 for this antibiotic). The low overall correlation coefficient for MICs for staphylococci $(0 \cdot 66$, Table 1$)$ reflects these discrepancies. A final area of major discrepancy was seen among results for 55 organisms that were very sensitive by the agar method (below the lowest concentration) but somewhat higher by Sensititre (first column, Sensititre concentrations 2 and 3, Table 2). Almost all the organisms in this group with Sensititre MICs of $0.03 \mathrm{mg} / 1$ (concentration 2 in Table 2) and above, and all those with higher Sensititre MICs, were streptococci, and the most extreme discrepancies were seen with ampicillin (Table 3).

In a few cases Sensititre results were lower than those from agar dilution. Only 17 organisms that appeared very sensitive by Sensititre had higher agar dilution MICs (row 1, solid medium concentrations 3 and 4, Table 2). These discrepancies were seen with Staph. aureus tested with fusidic acid and with coliforms tested with carbenicillin. Very few organisms appeared highly resistant by agar dilution and more sensitive by Sensititre (penultimate column, concentrations 8 and 9 , Table 2).

Table 3 Correlation of MICs determined by agar dilution and Sensititre

\begin{tabular}{|c|c|c|c|c|c|c|c|c|c|c|c|c|c|c|c|}
\hline \multirow[t]{2}{*}{ Organism } & \multirow[t]{2}{*}{ Antibiotic } & \multirow{2}{*}{$\begin{array}{l}\text { No. of } \\
\text { comparisons }\end{array}$} & \multicolumn{6}{|c|}{ Sensititre lower by } & \multicolumn{7}{|c|}{ Sensititre higher by } \\
\hline & & & $5^{*}$ & 4 & 3 & 2 & 1 & 0 & 1 & 2 & 3 & 4 & 5 & 6 & 7 \\
\hline Gram-negative bacilli & $\begin{array}{l}\text { Ampicillin } \\
\text { Carbenicillin } \\
\text { Cephaloridine } \\
\text { Gentamicin }\end{array}$ & $\begin{array}{l}172 \\
173 \\
170 \\
169\end{array}$ & & & $\begin{array}{l}3 \\
2\end{array}$ & $\begin{array}{r}10 \\
17 \\
4 \\
16\end{array}$ & $\begin{array}{l}13 \\
25 \\
17 \\
25\end{array}$ & $\begin{array}{r}120 \\
91 \\
119 \\
47\end{array}$ & $\begin{array}{l}19 \\
24 \\
24 \\
53\end{array}$ & $\begin{array}{r}7 \\
14 \\
4 \\
23\end{array}$ & $\begin{array}{l}2 \\
5\end{array}$ & & & & \\
\hline Staphylococci & $\begin{array}{l}\text { Penicillin } \\
\text { Cloxacillin } \\
\text { Fusidic acid } \\
\text { Gentamicin }\end{array}$ & $\begin{array}{l}175 \\
177 \\
176 \\
174\end{array}$ & & & $\begin{array}{l}2 \\
4 \\
1\end{array}$ & $\begin{array}{r}1 \\
12 \\
24 \\
8\end{array}$ & $\begin{array}{l}15 \\
57 \\
49 \\
35\end{array}$ & $\begin{array}{l}45 \\
78 \\
65 \\
38\end{array}$ & $\begin{array}{l}19 \\
26 \\
27 \\
46\end{array}$ & $\begin{array}{r}20 \\
2 \\
6 \\
24\end{array}$ & $\begin{array}{r}25 \\
0 \\
0 \\
17\end{array}$ & $\begin{array}{r}27 \\
1 \\
1 \\
5\end{array}$ & $\begin{array}{r}16 \\
1\end{array}$ & 3 & 2 \\
\hline Streptococci & $\begin{array}{l}\text { Penicillin } \\
\text { Ampicillin } \\
\text { Cephaloridine } \\
\text { Erythromycin }\end{array}$ & $\begin{array}{r}121 \\
127 \\
130 \\
129 \\
1893\end{array}$ & & & 12 & $\begin{array}{r}1 \\
1 \\
1 \\
95\end{array}$ & $\begin{array}{r}34 \\
19 \\
17 \\
26 \\
332\end{array}$ & $\begin{array}{r}70 \\
58 \\
84 \\
70 \\
885\end{array}$ & $\begin{array}{r}12 \\
27 \\
8 \\
10 \\
295\end{array}$ & $\begin{array}{r}4 \\
14 \\
18 \\
21 \\
157\end{array}$ & $\begin{array}{r}7 \\
2 \\
1 \\
59\end{array}$ & 0 & 1 & 1 & 2 \\
\hline
\end{tabular}

* Number of concentrations in doubling-dilution system. 
Considering each antibiotic for each organism in turn (Table 3 ), the best agreements of results were obtained for streptococci and penicillin $(96 \%$ within one dilution), for Gram-negative bacilli and cephaloridine ( $94 \%$ within one dilution), and for staphylococci and cloxacillin $(91 \%$ within one dilution). Good results (80-90\% within one dilution) were obtained for Gram-negative bacilli and ampicillin and carbenicillin; for staphylococci and fusidic acid; and for streptococci and ampicillin, cephaloridine, and erythromycin. There was somewhat inferior correlation for Gram-negative bacilli and staphylococci and gentamicin $(74 \%, 68 \%$ within on dilution) and poorest correlation (only $45 \%$ within one dilution) for staphylococci and penicillin.

A few results require comment in more detail. Gentamicin-sensitive Gram-negative bacilli and staphylococci usually appeared more resistant by the Sensititre system, but the reverse was more often true of more resistant organisms (MICs $>1-2 \mathrm{mg} / \mathrm{l}$ ). This could lead to confusion because, in many cases, MICs were close to those usually considered to indicate resistance.

Among the 44 staphylococci, 33 were known to be penicillinase producers. If $0.25 \mathrm{mg} / \mathrm{l}$ was taken as the dividing line between penicillin-sensitive and -resistant, five penicillinase-negative staphylococci in agar dilution tests and seven in broth dilution tests with MICs of $0.25 \mathrm{mg} / 1$ might have been considered resistant. On the other hand, while no penicillinaseproducing staphylococci had MICs below $0.25 \mathrm{mg} / 1$ in broth, two had MICs of $0.06 \mathrm{mg} / \mathrm{l}$ and two more MICs of $0.12 \mathrm{mg} / \mathrm{l}$ by agar dilution. Thus the Sensititre method was more reliable overall in distinguishing penicillinase-negative and -positive staphylococci. Five were also resistant to methicillin, but, as expected, testing with cloxacillin by both methods failed to detect most of these. Finally, staphylococci that had fusidic acid MICs of $0.5 \mathrm{mg} / 1$ or more by agar dilution often appeared more sensitive by Sensititre.

Very few discrepancies could be associated with particular media. The finding that carbenicillinsensitive Gram-negative bacilli were more sensitive by Sensititre than by agar dilution did not apply to MH media. On the other hand, two staphylococci appeared resistant to cloxacillin with $\mathrm{MH}$ media but not with the others. The sensitive staphylococci that appeared relatively resistant to gentamicin did so mainly on DST but not at all on WST and Isosensitest. It is of interest that these latter were incubated at $30^{\circ} \mathrm{C}$.

There was some evidence of instability of the antibiotics after three months' storage at room temperature. In 84 comparisons of immediate and delayed use, 46 agreed in that MICs were within one con- centration above or below the original; a further 26 gave results two to three concentrations above. In 11 comparisons, 10 of them with Gram-negative bacilli and either ampicillin, carbenicillin or cephaloridine, MICs were more than five concentrations higher.

There was some evidence that storage of plates at $-20^{\circ} \mathrm{C}$ might give better results. Tests on stored plates for 32 streptococci were, with only three exceptions, within one concentration of the original MIC.

To assess the reproducibility of results MICs were determined 50 times each for Streptococcus faecalis on three batches of plates; for E. coli NCTC10418 on five batches of plates; and for Staph. aureus (Oxford) on four batches of plates. Results were all within one concentration of the modal result for Strep. faecalis and penicillin, ampicillin, and erythromycin (the organism grew in all concentrations of cephaloridine); for $E$. coli with ampicillin, cephaloridine, and gentamicin; and for Staph. aureus with penicillin, cloxacillin, fusidic acid, and gentamicin. In three of the 50 tests with $E$. coli and carbenicillin results were two concentrations less than the modal MIC, but the rest fell within one concentration.

In a limited assessment of trays with revised ranges of antibiotic concentrations the higher concentrations of ampicillin, carbenicillin, and cephaloridine in the Gram-negative trays were most useful in providing convincing evidence that an organism was resistant where previously no decision could be made on borderline organisms. The main usefulness of the extra low concentrations in the staphylococcal and streptococcal trays was in enabling us to use the Oxford staphylococcus as a control organism. Previously it often failed to grow in any of the concentrations and was thus unsuitable. In addition, a more accurate determination of the low MICs of some streptococci was now possible.

The addition of salt to cloxacillin and the use of heavy inocula (6-hour broth culture diluted 10-fold) enabled us to detect resistance. There was still a problem, however, as the dried salt tended to 'jump' out of the wells when the seals were removed.

\section{Discussion}

Our experience with the Sensititre system suggests that it is robust and simple to use, versatile in that the dilution medium appears to make little difference, and accurate in that results are reproducible and compare well with those determined by agar dilution, allowing for the fact that liquid dilution systems usually produce slightly higher MICs than do agar dilution systems. The system can be adapted for the determination of bactericidal concentrations, but we 
have not studied this. However, several problems, some of them already solved, deserve attention.

It is particularly unfortunate that the streptococci, for which MICs are probably most often required, did not grow well in the system. The addition of serum, particularly to nutrient broth which seemed the best medium in our hands, helped but by no means solved the problem. A further search for a better medium is still required.

Problems of inoculum size also remain. We used the inoculum of $10^{6} \mathrm{cfu} / \mathrm{ml}$ recommended by the manufacturers, and this gave results comparable with those determined on solid medium. However, we failed to distinguish between some penicillinasepositive and penicillinase-negative staphylococci and we failed to detect methicillin-resistant staphylococci. The same problem might have been predicted with erythromycin-resistant staphylococci, but we did not experience it. An increase in inoculum size resulted in considerable improvement in results with penicillin and cloxacillin, and added sodium chloride improved results with cloxacillin still further. Incubation at $30^{\circ} \mathrm{C}$ did not yield convincing results in a few tests in which we used small inocula. However, a larger inoculum was unsuitable for other antibiotics.

We have no clear explanation of our difficulties with borderline resistance to fusidic acid among staphylococci and borderline resistance to gentamicin among staphylococci and Gram-negative bacilli. Results in all cases tended to be lower with the Sensititre system, making detection more difficult. It seems possible that inoculum size might influence these results, but we did not study the problem further.

The new ranges of antibiotic concentrations that we suggested were much more suitable than the original; they used all the available wells, leaving only one antibiotic-free control, and thus allowed an extension of the range of concentrations. A downward shift enabled us to use the Oxford staphylococcus as a control for Gram-positive organisms, and an upward shift enabled us to detect resistance more convincingly among Gram-negative organisms.

Our final reservation about the system concerns shelf life. All MICs tended to increase when 3-monthold trays kept at room temperature were used, but in some cases, largely among Gram-negative bacilli, results were highly misleading. On the basis of only a few tests, it seemed that storage at $-20^{\circ} \mathrm{C}$ might improve this.

None of the problems that we encountered seems insoluble given further study, and none of our reservations changes our original conclusion as to the potential usefulness of the system, particularly in a busy diagnostic laboratory that only infrequently determines MICs.

Requests for reprints to: Professor I. Phillips, Department of Microbiology, St. Thomas's Hospital Medical School, London SE1 7EH, UK 